\title{
Submitted: Indications for abdominal imaging: \\ Accepted: When and what to choose?
} 18.02.2020

Published: 31.03.2020

Keywords guidelines, point of care, ultrasound, computed tomography, magnetic resonance imaging

\author{
Cosmin Caraiani ${ }^{1}$, Dong Yi ${ }^{2}$, Bianca Petresc ${ }^{1}$, Christoph Dietrich ${ }^{3,4}$
}

${ }^{1}$ Department of Medical Imaging, "Iuliu Hatieganu" University of Medicine and Pharmacy, Cluj-Napoca, Romania

${ }^{2}$ Department of Ultrasound, Zhongshan Hospital, Fudan University, Shanghai, China

${ }^{3}$ Department Allgemeine Innere Medizin, Kliniken Hirlsanden Bern Beau Site, Salem und

Permanence, Switzerland

${ }^{4}$ Ultrasound Department, First Affiliated Hospital of Zhengzhou University, China

Correspondence: Department Allgemeine Innere Medizin (DAIM), Kliniken Hirslanden Beau Site, Salem und Permanence, Bern, Switzerland. Sino-German Research Center of Ultrasound in Medicine, The First Affiliated Hospital of Zhengzhou University, Zhengzhou, China; tel.: +41764408150,e-mail: c.f.dietrich@googlemail.com.

ORCID ID: orcid.org/0000-0001-6015-6347

DOI: $10.15557 / \mathrm{JoU} .2020 .0008$

\section{Abstract}

Imaging has a very important role in evaluating abdominal pathology. A good knowledge of indications is of crucial importance in the management of the patient with abdominal pathology. Ultrasound, which on its own can lead to an accurate diagnosis, plays a pivotal role in the management of abdominal pathology. The use of ultrasound contrast agents has significantly improved ultrasound diagnostic capacities in both hepatic and non-hepatic pathology. The use of computed tomography should be limited due to the potential harmful side effects of ionizing radiation, but it has established roles in evaluating severe abdominal traumatic and non-traumatic emergencies as well as in staging oncologic patients. Magnetic resonance imaging has very limited utility in abdominal emergencies due to difficulty of accessing the scanner and the long duration of the examination compared to computed tomography or ultrasound. However, magnetic resonance imaging has well-established clinical roles particularly for evaluating diffuse or focal hepatic pathology, benign and malignant bile duct pathology, pancreatic tumors, inflammatory bowel disease and rectal tumors. The aims of the following paper are to familiarize the clinician with the indications for imaging in abdominal pathology, to guide the clinician and radiologist in choosing the correct technique for a particular clinical situation, to prevent the overuse of imaging techniques and to prevent misdiagnosis of disease and incorrect therapy resulting from inappropriate imaging. 


\section{Introduction}

Ultrasound (US), computed-tomography (CT) and magnetic resonance imaging (MRI) all have important roles in evaluating abdominal pathology, with each technique having specific strengths and weaknesses. Table 1 provides a list of indications of imaging in abdominal pathology.

The authors have recently published two papers focusing on the appropriate use of imaging in abdominal pathology ${ }^{(1,2)}$. This paper completes the series and provides indications for each imaging technique. The aims of the following paper are:

- To familiarize the clinician with the indications for imaging in abdominal pathology;

- To guide the clinician and radiologist in choosing the correct technique for a particular clinical situation;

- To prevent overuse of imaging techniques;

- To prevent misdiagnosis of disease and incorrect therapy resulting from inappropriate imaging.

\section{Ultrasound}

Ultrasound is, in most cases, the first imaging technique used to diagnose and characterize abdominal pathology. Sometimes, ultrasound alone or with ultrasound contrast agents can be sufficient to make a complete diagnosis to enable management of the patient. The American Institute for Ultrasound in Medicine (AIUM) published the following indications for abdominal ultrasound, summarized in Tab. $2^{(3)}$

\section{Abdominal non-traumatic emergencies}

US is the most widely used imaging technique in abdominal emergencies ${ }^{(4)}$. It can be used in the setting of both acute and chronic pain. US excludes important pathology, and is sometimes the only imaging technique required to make a full diagnosis (e.g. in biliary lithiasis or cholecystitis). It can also guide decisions about further investigations. In the case of acute abdominal pain, different studies have shown that US adds $40 \%$ more information than clinical examination alone and changes the management in $20 \%$ of cases $^{(5)}$. Using US in patients with acute abdominal pain can decrease the number of emergency abdominal CT examinations by a half. The combined use of US and CT in patients with inconclusive US examinations in cases of acute abdominal pain will reduce the percentage of missed urgent diagnoses to $6 \%{ }^{(6)}$

\section{Jaundice}

Ultrasound is the imaging technique of choice in patients with jaundice. It can demonstrate obstruction by showing dilated biliary ducts, and sometimes it can identify the cause of obstruction. Sensitivity for the detection of

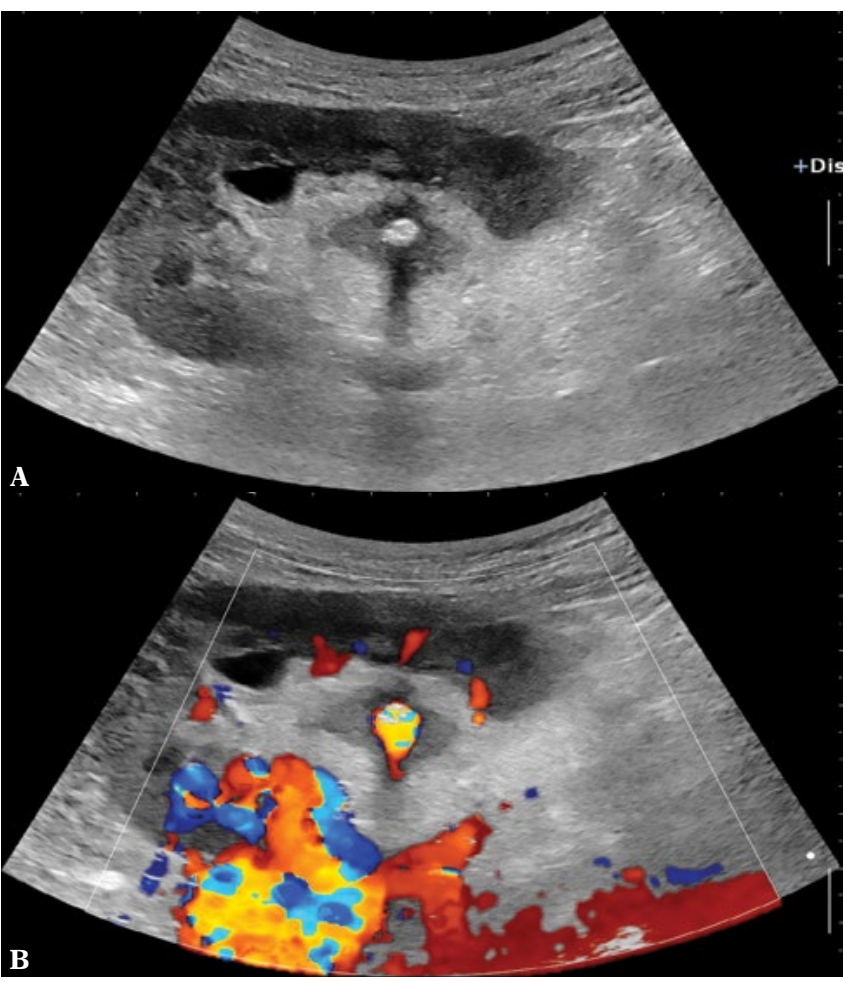

Fig. 1. Renal stone shown by B-mode (A) and color Doppler imaging (twinkling artefact $(\mathbf{B})$ )

choledocholithiasis varies considerably across different centers, with values between $25 \%$ and $100 \%$ being reported $^{(7)}$. Endoscopic ultrasound is the method of choice to rule out microlithiasis ${ }^{(8)}$.

\section{Urinary symptoms}

Ultrasound should be used in patients with symptoms related to the urinary tract, such as hematuria (Fig. 1). The most important indications for ultrasound in urinary tract infection are to check for complications, such as nephritic foci in the kidneys or renal abscesses, or to exclude an obstructive cause of pyelonephritis.

Sensitivity of conventional B-mode ultrasound in detecting renal tumors depends on the size and location of the tumor. In one study the detection rate was $65 \%$ for tumors $<2.5 \mathrm{~cm}$ and $80 \%$ for tumors $>2.5 \mathrm{~cm}^{(9)}$. Contrast-enhanced ultrasound (CEUS) results are comparable to contrast-enhanced CT for characterization of focal renal lesions. US has a sensitivity of $87.1 \%$ and a specificity of $98.1 \%$ in diagnosing bladder tumors ${ }^{(10)}$.

\section{Palpable abnormalities, such as abdominal} mass or organomegaly

Both US and CT are excellent techniques for confirming or excluding the presence of an abdominal mass, with sensitivity and specificity higher than $95 \%{ }^{(11)}$. The accuracy 
Tab. 1. Indications for a given imaging modality as per the category of abdominal pathology

\begin{tabular}{|c|c|c|c|c|}
\hline & Ultrasound & CEUS & CT & MRI \\
\hline $\begin{array}{l}\text { Abdominal } \\
\text { emergencies } \\
\text { (non-traumatic) }\end{array}$ & First-line imaging technique & & $\begin{array}{l}\text { Technique of choice if US is } \\
\text { inconclusive }\end{array}$ & $\begin{array}{l}\text { Can be used, as an alternative to CT in } \\
\text { selected cases (e.g. suspicion of acute } \\
\text { appendicitis), especially in children or } \\
\text { young patients }\end{array}$ \\
\hline $\begin{array}{l}\text { Abdominal } \\
\text { emergencies } \\
\text { (traumatic) }\end{array}$ & $\begin{array}{l}\text { First-line imaging technique in low- } \\
\text { energy trauma limited to the abdomen; } \\
\text { FAST technique for the detection of } \\
\text { hemoperitoneum, particularly useful in } \\
\text { unstable patients }\end{array}$ & $\begin{array}{l}\text { Improves the sensitivity of } \\
\text { US in detecting parenchymal } \\
\text { trauma and active } \\
\text { hemorrhage }\end{array}$ & $\begin{array}{l}\text { First-line imaging technique in } \\
\text { high-energy trauma }\end{array}$ & \\
\hline Jaundice & $\begin{array}{l}\text { First-line imaging technique. Confirms the } \\
\text { obstructive cause of jaundice by showing } \\
\text { bile duct dilatation }\end{array}$ & & $\begin{array}{l}\text { Can be used as a substitute } \\
\text { if MRl is not available. Low } \\
\text { sensitivity for bile duct calculi }\end{array}$ & Technique of choice if US is inconclusive \\
\hline Urinary symptoms & $\begin{array}{l}\text { First-line imaging technique. Confirms the } \\
\text { presence of hydronephrosis }\end{array}$ & & $\begin{array}{l}\text { Technique of choice for the } \\
\text { diagnosis of renal or ureteral } \\
\text { calculi }\end{array}$ & \\
\hline $\begin{array}{l}\text { Palpable abnormality } \\
\text { (abdominal mass or } \\
\text { organomegaly) }\end{array}$ & $\begin{array}{l}\text { First-line imaging technique for } \\
\text { confirming hepato- or splenomegaly. Can } \\
\text { be used to exclude an abdominal mass in } \\
\text { order to avoid excessive irradiation by CT }\end{array}$ & & $\begin{array}{l}\text { Technique of choice for } \\
\text { characterizing an abdominal } \\
\text { mass discovered by US or } \\
\text { clinical examination. }\end{array}$ & $\begin{array}{l}\text { Can be used as a substitute for } C T \text { in } \\
\text { selected cases. Technique of choice for } \\
\text { characterizing pelvic masses. }\end{array}$ \\
\hline $\begin{array}{l}\text { Elevated liver } \\
\text { enzymes }\end{array}$ & $\begin{array}{l}\text { Imaging technique of choice for } \\
\text { diagnosing and characterization of diffuse } \\
\text { liver disease }\end{array}$ & & & $\begin{array}{l}\text { Complementary to US; can be used to } \\
\text { quantify diffuse liver disease }\end{array}$ \\
\hline $\begin{array}{l}\text { Staging and } \\
\text { evaluation of already } \\
\text { known oncologic } \\
\text { disease }\end{array}$ & & $\begin{array}{l}\text { Used in the characterization } \\
\text { of indeterminate liver lesions } \\
\text { seen on CT }\end{array}$ & $\begin{array}{l}\text { Technique of choice, both for } \\
\text { baseline imaging and also for } \\
\text { follow-up }\end{array}$ & $\begin{array}{l}\text { Used complementary to } \mathrm{CT} \text { for the } \\
\text { characterization of indeterminate lesions, } \\
\text { particularly focal liver lesions }\end{array}$ \\
\hline $\begin{array}{l}\text { Evaluation of } \\
\text { suspected congenital } \\
\text { abnormalities }\end{array}$ & $\begin{array}{l}\text { First-line imaging technique, both ante- } \\
\text { and postnatal }\end{array}$ & & $\begin{array}{l}\text { Used in the characterization } \\
\text { of complex urinary tract } \\
\text { malformations }\end{array}$ & $\begin{array}{l}\text { Better characterization of abnormalities, } \\
\text { incompletely evaluated by US. Can be } \\
\text { used both ante- and postnatally }\end{array}$ \\
\hline $\begin{array}{l}\text { Pre- and post- } \\
\text { transplantation } \\
\text { evaluation }\end{array}$ & $\begin{array}{l}\text { Can be used in the follow-up of } \\
\text { transplanted patients in order to avoid } \\
\text { excessive irradiation }\end{array}$ & $\begin{array}{l}\text { Improves US sensitivity } \\
\text { in depicting vascular } \\
\text { complications in the } \\
\text { transplanted patient }\end{array}$ & $\begin{array}{l}\text { Technique of choice due to its } \\
\text { better suitability in assessing } \\
\text { vascular structures }\end{array}$ & \\
\hline $\begin{array}{l}\text { Guiding of } \\
\text { interventional } \\
\text { procedures }\end{array}$ & Technique of choice & $\begin{array}{l}\text { Can be used to improve } \\
\text { US-guided procedures (e.g. } \\
\text { avoid the punction of the } \\
\text { necrotized area in necrotic } \\
\text { tumors) }\end{array}$ & $\begin{array}{l}\text { Second-line technique in } \\
\text { cases when US cannot guide } \\
\text { the procedure (lesion not } \\
\text { identifiable by US, or vascular/ } \\
\text { digestive interpositions) }\end{array}$ & \\
\hline $\begin{array}{l}\text { Evaluation of } \\
\text { peritoneal and } \\
\text { retroperitoneal fluid }\end{array}$ & $\begin{array}{l}\text { First-line imaging technique, both ante- } \\
\text { and postnatal }\end{array}$ & & $\begin{array}{l}\text { Used in the characterization } \\
\text { of complex urinary tract } \\
\text { malformations }\end{array}$ & $\begin{array}{l}\text { Better characterization of abnormalities, } \\
\text { incompletely evaluated by US. Can be } \\
\text { used both ante- and postnatally }\end{array}$ \\
\hline $\begin{array}{l}\text { Postoperative } \\
\text { complications }\end{array}$ & First-line imaging technique & & $\begin{array}{l}\text { Can be used for better } \\
\text { characterization of } \\
\text { abnormalities, such } \\
\text { as collections or free } \\
\text { fluid, discovered } \\
\text { by ultrasound, for } \\
\text { characterization } \\
\text { of inconclusive US } \\
\text { findings or in cases of } \\
\text { discrepancy between US } \\
\text { and the clinical status of } \\
\text { the patient }\end{array}$ & \\
\hline
\end{tabular}




\begin{tabular}{|c|c|c|c|c|}
\hline $\begin{array}{l}\text { Follow-up of liver } \\
\text { cirrhosis and } \\
\text { characterization of } \\
\text { liver nodules in the } \\
\text { cirrhotic liver }\end{array}$ & $\begin{array}{l}\text { First-line imaging technique, used } \\
\text { for the detection of liver nodules } \\
\text { on the cirrhotic liver }\end{array}$ & $\begin{array}{l}\text { Characterization of liver } \\
\text { nodules discovered by } \\
\text { routine US }\end{array}$ & $\begin{array}{l}\text { Characterization of liver } \\
\text { nodules discovered by } \\
\text { routine US }\end{array}$ & $\begin{array}{l}\text { Characterization of liver nodules } \\
\text { discovered by routine US }\end{array}$ \\
\hline $\begin{array}{l}\text { Evaluation of } \\
\text { abdominal vessels }\end{array}$ & $\begin{array}{l}\text { Can be used in the follow-up of } \\
\text { ectatic abdominal aorta to avoid } \\
\text { overirradiation }\end{array}$ & & $\begin{array}{l}\text { Technique of } \\
\text { choice for the initial } \\
\text { characterization and } \\
\text { follow-up of abdominal } \\
\text { aortic aneurysms }\end{array}$ & \\
\hline $\begin{array}{l}\text { Characterization } \\
\text { of incidentally } \\
\text { discovered focal liver } \\
\text { lesions }\end{array}$ & & $\begin{array}{l}\text { In experienced centers, } \\
\text { it can represent the } \\
\text { first-line imaging } \\
\text { technique for } \\
\text { characterization of } \\
\text { focal liver lesions }\end{array}$ & $\begin{array}{l}\text { Substitute to MRI in } \\
\text { cases when MRI is not } \\
\text { available or not feasible }\end{array}$ & $\begin{array}{l}\text { Technique of choice in cases of } \\
\text { inconclusive CEUS findings }\end{array}$ \\
\hline Liver infections & $\begin{array}{l}\text { First-line imaging technique for } \\
\text { the detection of liver abscess or } \\
\text { hydatid cyst }\end{array}$ & $\begin{array}{l}\text { It can be used, as } \\
\text { a second-line imaging } \\
\text { technique for the } \\
\text { differentiation between } \\
\text { infectious lesions and } \\
\text { other focal liver lesions }\end{array}$ & $\begin{array}{l}\text { It can be used, as } \\
\text { a second-line imaging } \\
\text { technique for the } \\
\text { differentiation between } \\
\text { infectious lesions and } \\
\text { other focal liver lesions }\end{array}$ & $\begin{array}{l}\text { It can be used, as a second- } \\
\text { line imaging technique for the } \\
\text { differentiation between infectious } \\
\text { lesions and other focal liver } \\
\text { lesions }\end{array}$ \\
\hline $\begin{array}{l}\text { Evaluation of } \\
\text { pancreatic tumors }\end{array}$ & $\begin{array}{l}\text { Endoscopic US can be used } \\
\text { complementary to CT as } \\
\text { a second-line technique to } \\
\text { evaluate inconclusive CT findings }\end{array}$ & & $\begin{array}{l}\text { Technique of choice } \\
\text { for staging pancreatic } \\
\text { tumors }\end{array}$ & $\begin{array}{l}\text { It can be used to clarify } \\
\text { inconclusive } \mathrm{CT} \text { findings, } \\
\text { particularly in the case of cystic } \\
\text { pancreatic tumors }\end{array}$ \\
\hline $\begin{array}{l}\text { Inflammatory bowel } \\
\text { disease }\end{array}$ & $\begin{array}{l}\text { US and MRI have complementary } \\
\text { roles in the initial evaluation and } \\
\text { in the subsequent follow-up of } \\
\text { patients with inflammatory bowel } \\
\text { disease }\end{array}$ & & $\begin{array}{l}\text { CT can be used as } \\
\text { a substitute for MRI } \\
\text { due to its better spatial } \\
\text { resolution; its usage } \\
\text { should be limited to } \\
\text { cases when MRI is not } \\
\text { available or not feasible } \\
\text { due to the fact that } \\
\text { patients with IBD are in } \\
\text { most cases adolescents } \\
\text { or young adults and it is } \\
\text { recommended to avoid } \\
\text { irradiation in those } \\
\text { patients }\end{array}$ & $\begin{array}{l}\text { US and MRI have complementary } \\
\text { roles in the initial evaluation and } \\
\text { in the subsequent follow-up of } \\
\text { patients with inflammatory bowel } \\
\text { disease }\end{array}$ \\
\hline $\begin{array}{l}\text { Local staging of rectal } \\
\text { tumors }\end{array}$ & $\begin{array}{l}\text { Endoscopic US can be used } \\
\text { complementary to MRI for the } \\
\text { characterization of rectal wall } \\
\text { invasion (differentiation between } \\
\text { T1/T2/T3a tumors) }\end{array}$ & & & $\begin{array}{l}\text { Technique of choice for local } \\
\text { staging of rectal cancer; } \\
\text { evaluation for distant metastases } \\
\text { is done by CT as for every } \\
\text { abdominal or pelvic malignancy }\end{array}$ \\
\hline Perianal fistulas & & & & $\begin{array}{l}\text { Technique of choice for the } \\
\text { evaluation of perianal fistulas }\end{array}$ \\
\hline
\end{tabular}


of US in determining the organ of origin is estimated at between $88 \%$ and $91 \%{ }^{(11)}$.

\section{Elevated liver enzymes}

For patients with elevated liver enzymes, ultrasound should be the first imaging technique used. US performs well in the diagnosis of diffuse liver disease, with a sensitivity $>90 \%$ for the diagnosis of advanced liver cirrhosis with complications $^{(12)}$.

Follow-up of already diagnosed and documented abdominal pathology

US is recommended as a follow-up technique for ectatic abdominal aorta (diameter between 2.6 and $2.9 \mathrm{~cm}$ ). Aneurysms with a diameter $>3 \mathrm{~cm}$ should be examined by CT. In pancreatitis, the first evaluation is often done by means of CT. Ultrasound is useful in follow-up since frequent $\mathrm{CT}$ scans lead to excessive irradiation exposure.

\section{Staging and evaluation of known oncologic pathology}

Where there is good visualization of the liver, contrastenhanced ultrasound has a comparable sensitivity to contrast-enhanced CT or MRI for the diagnosis of liver metastasis. CEUS of the liver has been shown to detect more metastases in the follow-up of colorectal metastases than conventional B-mode US ${ }^{(13)}$.

\section{Evaluation of suspected congenital abnormalities}

Congenital abnormalities can be diagnosed with both antenatal and postnatal US evaluations. Ultrasound is typically the first imaging method used in urinary tract congenital abnormalities because of its easy availability, non-invasiveness and the fact that it is free from ionizing radiation. CT and MRI are indicated in complex urinary malformations to evaluate the collecting system and vascular anatomy.

\section{Abdominal trauma}

CEUS has significantly improved the diagnostic performance of US in the diagnosis of parenchymal organ injuries, with sensitivity and specificity of $>90 \%$ and up to $99 \%$ under certain circumstances; the performance is then similiar to that of CT. CEUS can prevent overutilization of $\mathrm{CT}^{(14)}$. Ultrasound is generally used as the diagnostic tool of choice in low-energy trauma limited to the abdomen. In a series of 57 patients with blunt abdominal trauma, the diagnostic accuracy of ultrasound in evaluating the existence of peritoneal fluid was $91 \%$, although it was only $56 \%$ for the evaluation of parenchymal injury. However, another study reported considerably better accuracy, with a value of $94.7 \%$ for the combined presence of parenchymal injury and free peritoneal fluid ${ }^{(15)}$. The different results reported may be due to differences in experience between operators and centers. Focused Assessment with Sonography for Trauma (FAST) shows high sensitivity up to $99 \%$ for the detection of free fluid, but the sensitivity in the diagnosis of parenchymal injuries is poor.

\section{Pre-transplantation and post-transplantation evaluation}

Ultrasound is an additional method to CT for pre- and post-transplantation evaluations. CT is considered the technique of choice due to its better suitability for assessing vascular structures. US can be used in diagnosis and follow-up of non-vascular complications of transplants, such as abscesses or the presence of free fluid.

\section{Interventional procedures}

US can be used for guiding both diagnostic and interventional procedures in abdominal pathology. Interventional US benefits from the development of new techniques, such as fusion imaging (a technique that uses data from two different imaging modalities to improve the quality of information for increased diagnostic accuracy) and CEUS. The complication rate in interventional ultrasound is low, ranging from $0.51 \%$ to $0.81 \%$ in US-guided fine needle biopsy, although the rate ranges from $0.4 \%$ to $2.5 \%$ when a needle with a diameter over $1 \mathrm{~mm}$ is used $^{(16)}$.

\section{Evaluation of peritoneal or retroperitoneal fluid}

Ultrasound is the method of choice for the detection, quantification and localization of peritoneal fluid, with results superior to CT. US can detect even small amounts of fluid in the peritoneum ${ }^{(17)}$.

\section{Abdominal emergencies in children}

Ultrasound is the recommended imaging method for the diagnosis of abdominal emergencies in newborns and young children, such as hypertrophic pyloric stenosis or intussusception. For suspected hypertrophic pyloric stenosis, ultrasound, in experienced hands, has sensitivity and accuracy close to $100 \%$ and a diagnostic accuracy of $97 \%-100 \%$ for the diagnosis of intussusception ${ }^{(18)}$. In children, ultrasound is also the technique of choice to identify treatable abnormalities that favor upper urinary tract infections, other than vesico-ureteral reflux. Contrast-enhanced voiding urosonography is replacing radiographic voiding 
Tab. 2. Indications for abdominal ultrasound [AIUM Practice Parameter for the Performance of an Ultrasound Examination of the Abdomen and/or Retroperitoneum. http://www.aium.org/resources/guidelines/abdominal.pdf]

\begin{tabular}{|l|}
\hline Abdominal, flank, and/or back pain \\
\hline Signs or symptoms that may be referred from the abdominal and/or retroperitoneal regions, such as jaundice or hematuria \\
\hline Palpable abnormalities, such as an abdominal mass or organomegaly \\
\hline Abnormal laboratory values or abnormal findings on other imaging examinations suggestive of abdominal and/or retroperitoneal pathology \\
\hline Follow-up of known or suspected abnormalities in the abdomen and/or retroperitoneum \\
\hline $\begin{array}{l}\text { Evaluation of cirrhosis, portal hypertension, and transjugular intrahepatic portosystemic shunt (TIPS) stents; screening for hepatoma; and evaluation of } \\
\text { the liver in conjunction with liver elastography }\end{array}$ \\
\hline Abdominal trauma \\
\hline Search for metastatic disease or an occult primary neoplasm \\
\hline Evaluation of urinary tract infection and hydronephrosis \\
\hline Evaluation of uncontrolled hypertension and suspected renal artery stenosis \\
\hline Search for the presence of free or loculated peritoneal and/or retroperitoneal fluid \\
\hline Evaluation of suspected congenital abnormalities \\
\hline Evaluation of suspected hypertrophic pyloric stenosis, intussusception, necrotizing enterocolitis, or any other bowel abnormalities \\
\hline Pretransplantation and posttransplantation evaluation \\
\hline Planning for and guiding an invasive procedure \\
\hline
\end{tabular}

Tab. 3. Indications for abdominal CT [ACR-SPR Practice Parameter for the performance of computed tomography (CT) of the abdomen and computed tomography (CT) of the pelvis; https://www.acr.org/-/media/ACR/Files/Practice-Parameters/ct-abd-pel.pdf]

\begin{tabular}{|l|}
\hline Evaluation of abdominal, flank, or pelvic pain, including evaluation of suspected or known urinary calculi and appendicitis \\
\hline Evaluation of abdominal or pelvic trauma \\
\hline Evaluation of renal and adrenal masses and of urinary tract abnormalities with CT urography \\
\hline Evaluation of known or suspected abdominal or pelvic masses or fluid collections, including gynecological masses \\
\hline Evaluation of primary or metastatic malignancies, including lesion characterization (e.g. focal liver lesion), staging, and treatment monitoring \\
\hline $\begin{array}{l}\text { Surveillance following locoregional therapies in abdominal malignancies, including percutaneous ablation, intra-arterial therapies (transarterial chemo- } \\
\text { embolization, selective internal radiation therapy), and targeted image-guided radiation therapy }\end{array}$ \\
\hline Assessment for recurrence of tumors following surgical resection \\
\hline Detection of complications following abdominal and pelvic surgery, e.g. abscess, lymphocele, radiation change, and fistula/sinus tract formation \\
\hline Evaluation of diffuse liver disease (e.g. cirrhosis, steatosis, iron deposition disease) and biliary system, including CT cholangiography) \\
\hline $\begin{array}{l}\text { Evaluation of abdominal or pelvic inflammatory processes, including inflammatory bowel disease, infectious bowel disease and its complications, } \\
\text { without or with CT enterography }\end{array}$ \\
\hline Assessment of abnormalities of abdominal or pelvic vascular structures; noninvasive angiography of the aorta and its branches and noninvasive venography \\
\hline Clarification of findings from other imaging studies or laboratory abnormalities \\
\hline Evaluation of known or suspected congenital abnormalities of abdominal or pelvic organs \\
\hline Evaluation for bowel obstruction or Gl bleeding \\
\hline Screening and diagnostic evaluation for colonic polyps and cancers with CT colonography \\
\hline Guidance for interventional or therapeutic procedures within the abdomen or pelvis \\
\hline Follow-up evaluation after interventional or therapeutic procedures within the abdomen or pelvis, including abscess drainage \\
\hline Treatment planning for radiation and chemotherapy and evaluation of tumor response to treatment, including perfusion studies \\
\hline Pre- and post-transplant assessment \\
\hline
\end{tabular}

cystourethrography as the technique of choice in diagnosing vesico-ureteral reflux.

\section{The usage of contrast-enhanced ultrasound (CEUS)}

CEUS is indicated in both hepatic and non-hepatic pathology. The role of CEUS in characterizing focal liver lesions is well-established. When US is technically satisfactory, it offers comparable results to those of CT and MRI. A large multicenter study showed the value of CEUS in the characterization of focal liver lesions ${ }^{(19)}$. CEUS has also proved its value in renal, pancreatic and small bowel pathology. In most of the cases evaluated by CEUS, ultrasound contrast agents (UCA) are administered intravenously. Intracavitary administration of UCA can also offer useful diagnostic information. UCAs can be injected in physiologic cavities, such as the bladder for vesico-ureteral reflux or the uterine cavity for assessing tubal patency or in pathologic cavities for the characterization of fistulae. CEUS can be used intraoperatively especially in gastrointestinal surgery, but also in neurosurgery and interventional procedures, such as biopsies and interstitial ablation therapies which can be guided using CEUS.

\section{Computed tomography}

CT is indicated in many abdominal conditions because of its excellent morphological resolution and its ability 
Tab. 4. Indications for abdominal MRI [ACR-SAR-SPR Practice Parameter for the performance of Magnetic Resonance Imaging (MRI) of the abdomen (Excluding the Liver); https://www.acr.org/-/media/ACR/Files/Practice-Parameters/mr-abd.pdf and ACR-SAR-SPR Practice Parameter for the performance of Magnetic Resonance Imaging (MRI) of the liver; https://www.acr.org/-/media/ACR/Files/ Practice-Parameters/mr-liver.pdf]

\begin{tabular}{|c|c|}
\hline \multirow{12}{*}{ Liver } & Detection of focal hepatic lesions \\
\hline & $\begin{array}{l}\text { Focal hepatic lesion characterization, e.g. cyst, focal fat, hemangiomas, and vascular malformations, hepatocellular } \\
\text { carcinoma (HCC), hepatoblastoma, metastasis, cholangiocarcinoma, focal nodular hyperplasia, and hepatic adenoma }\end{array}$ \\
\hline & Evaluation for known or suspected metastasis \\
\hline & Evaluation of vascular patency, including Budd-Chiari and portal vein thrombosis \\
\hline & Evaluation of chronic liver disease, such as hemochromatosis, hemosiderosis, or steatosis \\
\hline & Evaluation of cirrhotic liver and HCC surveillance \\
\hline & $\begin{array}{l}\text { Clarification of findings from other imaging studies, laboratory abnormalities, or alternative imaging for } \\
\text { contraindications to CT scans }\end{array}$ \\
\hline & Evaluation of infection \\
\hline & $\begin{array}{l}\text { Potential liver donor evaluation, liver resection evaluation, liver transplant evaluation, and evaluation of postsurgical } \\
\text { complications }\end{array}$ \\
\hline & $\begin{array}{l}\text { Evaluation of tumor response to treatment, e.g. image-guided liver interventions/tumor ablation, } \\
\text { chemoembolization, radioembolization, chemotherapy, radiotherapy, or surgery }\end{array}$ \\
\hline & Evaluation of known or suspected congenital abnormalities \\
\hline & Informing or guiding clinical decision-making and treatment planning \\
\hline \multirow{8}{*}{ Pancreas } & Detection and preoperative assessment of pancreatic neoplasms \\
\hline & Characterization of indeterminate lesions and/or unexplained enlargement detected with other imaging modalities \\
\hline & Identification of causes of pancreatic duct obstruction, including calculi, stricture, or mass \\
\hline & Detection and characterization of pancreatic duct anomalies \\
\hline & Evaluation of pancreatic or peripancreatic fluid collections or fistulae \\
\hline & Evaluation of chronic pancreatitis, including assessment of pancreatic exocrine function \\
\hline & Evaluation of complicated acute pancreatitis and associated complications \\
\hline & Postoperative treatment/follow-up after pancreatic surgery \\
\hline \multirow{3}{*}{ Spleen } & Characterization of indeterminate lesions detected with other imaging modalities \\
\hline & Detection and characterization of suspected diffuse abnormalities of the spleen \\
\hline & Evaluation of suspected accessory splenic tissue \\
\hline \multirow{12}{*}{$\begin{array}{l}\text { Kidneys, ureters and } \\
\text { retroperitoneum }\end{array}$} & Detection of renal tumors \\
\hline & Characterization of indeterminate lesions detected with other imaging modalities \\
\hline & Preoperative assessment of renal neoplasms to include evaluation of the arterial supply, renal vein, and inferior vena cava \\
\hline & Evaluation of the urinary tract for abnormalities of anatomy or physiology (MR urography) \\
\hline & Postprocedure surveillance after renal tumor ablation or surgical extirpation via partial or complete nephrectomy \\
\hline & Evaluation of ureteral abnormalities \\
\hline & Evaluation of suspected retroperitoneal fibrosis and other benign lesions \\
\hline & Characterization and staging of retroperitoneal malignant neoplasms \\
\hline & Evaluation or follow-up of lymphadenopathy \\
\hline & Surveillance imaging of the upper urinary tract in patients with urothelial carcinoma \\
\hline & Characterization of complex congenital anomalies \\
\hline & Identification of causes of urinary tract obstruction \\
\hline \multirow{4}{*}{ Adrenal glands } & Detection of suspected pheochromocytoma and functioning adrenal adenoma \\
\hline & Characterization of indeterminate lesions detected with other imaging modalities \\
\hline & Staging of malignant adrenal neoplasms \\
\hline & Detection and characterization of congenital anomalies \\
\hline
\end{tabular}




\begin{tabular}{|c|c|}
\hline \multirow{7}{*}{ Vascular } & Diagnosis and/or assessment of the following vascular abnormalities: \\
\hline & I. Aneurysm of the aorta and major branch vessels; \\
\hline & $\begin{array}{l}\text { II. Stenosis or occlusion of the aorta and major branch vessels resulting from atherosclerotic disease, thromboembolic } \\
\text { disease, or large vessel vasculitis; }\end{array}$ \\
\hline & III. Dissection of the aorta; \\
\hline & IV. Vascular malformation and arteriovenous fistula; \\
\hline & V. Portal, mesenteric or splenic vein thrombosis; \\
\hline & VI. Inferior vena cava (IVC), pelvic vein, gonadal vein, renal vein or hepatic vein thrombosis \\
\hline & Vascular evaluation in one of the following clinical scenarios: \\
\hline & I. Lower extremity claudication; \\
\hline & II. Known or suspected renovascular hypertension; \\
\hline & III. Known or suspected chronic mesenteric ischemia; \\
\hline & IV. Hemorrhagic hereditary telangiectasia; \\
\hline & V. Known or suspected Budd-Chiari syndrome; \\
\hline & VI. Portal hypertension; \\
\hline & VII. Known or suspected gonadal vein reflux \\
\hline & Preprocedure assessment for the following: \\
\hline & I. Vascular mapping prior to living organ donation a) Liver b) Kidney c) Pancreas d) Combined organ transplant; \\
\hline & II. Assessment of renal vein and IVC patency in the setting of renal malignancy or neoplasm; \\
\hline & III. Vascular mapping prior to placement of or surgery on a transjugular intrahepatic portosystemic shunt (TIPS); \\
\hline & IV. Vascular mapping prior to resection of abdominal and pelvic neoplasms; \\
\hline & V. Vascular mapping prior to uterine fibroid embolization; \\
\hline & VI. Vascular mapping prior to hepatic bland embolization, chemoembolization, and radioembolization procedures; \\
\hline & VII. Vascular mapping prior to tissue grafting \\
\hline & Postprocedure assessment for the following: \\
\hline & I. Evaluation of organ transplant vascular anastomoses (hepatic, renal, and pancreatic); \\
\hline & II. Detection of suspected leak following aortic aneurysm surgery or MR-compatible aortic stent graft placement; \\
\hline & III. Evaluation of ovarian artery collateral flow following uterine fibroid embolization \\
\hline \multirow{5}{*}{$\begin{array}{l}\text { Bile ducts } \\
\text { and gallbladder }\end{array}$} & Detection, staging, and post-treatment follow-up of bile duct and gallbladder cancer \\
\hline & Detection of bile duct or gallbladder stones \\
\hline & Evaluation of bile duct dilation and/or narrowing \\
\hline & Evaluation of suspected congenital abnormalities of the gallbladder or bile ducts \\
\hline & Detection and anatomic delineation of bile leaks \\
\hline \multirow{7}{*}{$\begin{array}{l}\text { Gastrointestinal tract and } \\
\text { peritoneum }\end{array}$} & Preoperative assessment of gastric neoplasms \\
\hline & Detection of small bowel neoplasms \\
\hline & Assessment of inflammatory disorders of the small or large bowel and mesentery (including MR enterography); \\
\hline & Assessment of peritoneal adhesive disease \\
\hline & Detection and evaluation of primary and metastatic peritoneal or mesenteric neoplasms \\
\hline & $\begin{array}{l}\text { Detection and characterization of intra-abdominal fluid collections, as well as follow-up after percutaneous or surgical } \\
\text { drainage }\end{array}$ \\
\hline & Evaluation and follow-up of lymphadenopathy \\
\hline \multirow{8}{*}{ Other applications } & $\begin{array}{l}\text { Imaging follow-up of abnormalities of the abdomen deemed indeterminate on initial MRI and for which } \\
\text { surgery is not advised }\end{array}$ \\
\hline & Detection and characterization of extraperitoneal neoplasms other than above \\
\hline & $\begin{array}{l}\text { Evaluation of the abdomen as an alternative to computed tomography }(\mathrm{CT}) \text { when radiation exposure is an overriding } \\
\text { concern in susceptible patients, such as pregnant or pediatric patients, or in patients with a contraindication to } \\
\text { iodinated contrast agents }\end{array}$ \\
\hline & Assessment of treatment response to medical therapy of malignant neoplasms of the abdomen \\
\hline & $\begin{array}{l}\text { Determining the organ of origin of an indeterminate (benign or malignant) lesion in the abdomen when the origin is } \\
\text { not obvious from other imaging modalities }\end{array}$ \\
\hline & Identification and characterization of vascular malformations \\
\hline & Evaluation of abdominal wall abnormalities not adequately assessed by other imaging modalities \\
\hline & Assessment of traumatic injury of the abdomen when $\mathrm{CT}$ is contraindicated \\
\hline
\end{tabular}



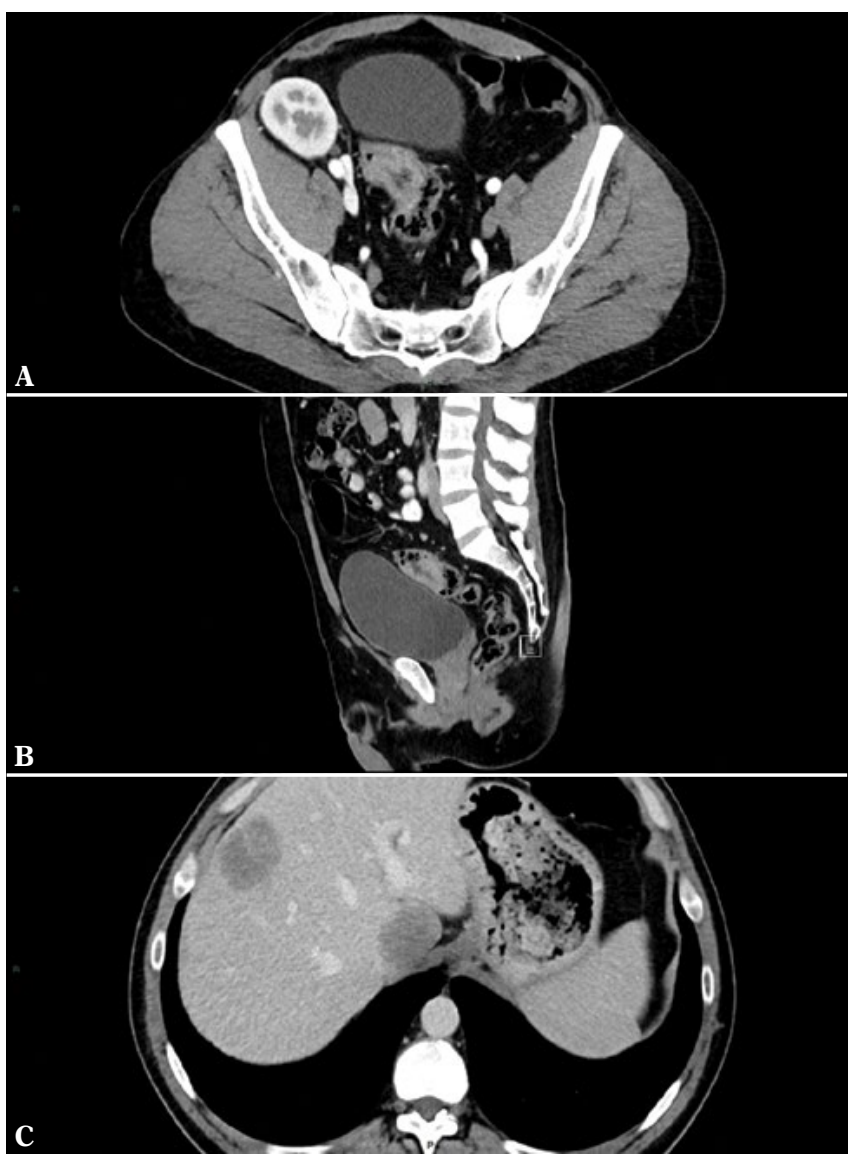

Fig. 2. CT in the initial staging of a rectosigmoid junction tumon Axial (A) and sagittal (B) sections through the tumor. Axial section in the upper abdomen (C) showing the presence of liver metastases

to image many different structures, such as abdominal viscera, pelvic organs, lungs and bones, with a single examination. The presence of ionizing radiation limits the usage of CT. The American College of Radiologists (ACR) has summarized the indications for abdominal CT $(\text { Tab. 3) })^{(20)}$.

\section{Evaluation of non-traumatic abdominal emergencies}

CT has both very good sensitivity and specificity in diagnosing urinary lithiasis, even if low-dose protocols are used. The sensitivity of low-dose abdominal CT in the diagnosis of urolithiasis ranges from 90 to $98 \%$, with only very small calculi (smaller than $3 \mathrm{~mm}$ ) being missed. Specificity of low-dose CT in the diagnosis of urinary calculi ranges from 88 to $100 \%{ }^{(21)}$. Bowel obstruction, suspicion of gastric or bowel perforation or lower gastrointestinal tract hemorrhage are also evaluated by CT. The accuracy of CT in diagnosing pneumoperitoneum is as high as $99 \%{ }^{(22)}$. A meta-analysis found that CT angiography has a sensitivity of $82.5 \%$ and a specificity of $92.1 \%$ in detecting gastrointestinal bleeding ${ }^{(23)}$. The sensitivity of CT angiography in determining the underlying cause of gastrointestinal bleeding has been reported to be above $90 \%$ in multiple studies. Sensitivity and specificity of CT in the diagnosis of small bowel obstruction range from 81 to $100 \%$ and from 68 to $100 \%$, respectively ${ }^{(24)}$. CT has a lower sensitivity, estimated at $82 \%$, for the diagnosis of enteromesenteric ischemia, a potentially letal condition ${ }^{(25)}$.

\section{Evaluation of abdominal or pelvic trauma}

The use of CT imaging reduces morbidity and mortality in hemodynamically stable patients with high-energy and severe multi-trauma and is, therefore, the standard technique. Clinical examination is notoriously unreliable in abdominal trauma, particularly in bowel and pancreatic injuries, and the misdiagnosis of these lesions is a wellknown cause of increased morbidity and mortality in patients who survive the initial phases of multiple trauma. The addition of CT to diagnostic protocols of patients with abdominal trauma will lead to a substantial decrease, of approximately $20 \%$, of missed injuries by means of clinical examination and abdominal ultrasound.

\section{CT has some disadvantages:}

1. the patient needs to be hemodynamically stable and able to lie still for the examination;

2. it may utilize iodinated contrast media;

3. it involves radiation exposure.

The latter is an important limiting factor, especially when there is a low-risk mechanism of injury and the patient's condition would not necessarily warrant a CT examination, even though an imaging investigation is required. If possible, minor abdominal trauma should be managed by means of ultrasound and clinical surveillance, while CT is mandatory for major abdominal trauma or polytrauma. CT has good accuracy in the evaluation of solid abdominal visceral trauma and bowel/mesenteric trauma. Different papers report a sensitivity of CT ranging between 92 and $98 \%$ in depicting liver and spleen injuries ${ }^{(26)}$. For small bowel and mesenteric injuries, CT is reported to have a sensitivity that varies between 70 and $95 \%$ and specificity between 92 and $100 \%{ }^{(27)}$. The sensitivity of CT in pancreatic injuries has been reported by different authors to range from 70 to $95 \%{ }^{(28)}$. CT can visualize the existence of active hemorrhage by showing contrast media extravasation.

\section{Evaluation of urinary symptoms}

CT has both better sensitivity and specificity than ultrasound in the diagnosis of renal tumors. The sensitivity of CT in detection of small renal masses is higher than $90 \%$ and approaches $100 \%$ in tumors larger than $2 \mathrm{~cm}^{(29)}$.

\section{Diagnosis and follow-up of oncologic patients}

CT is a useful imaging tool when there is a suspicion of tumor in the abdomen or pelvis and also for follow-up of 

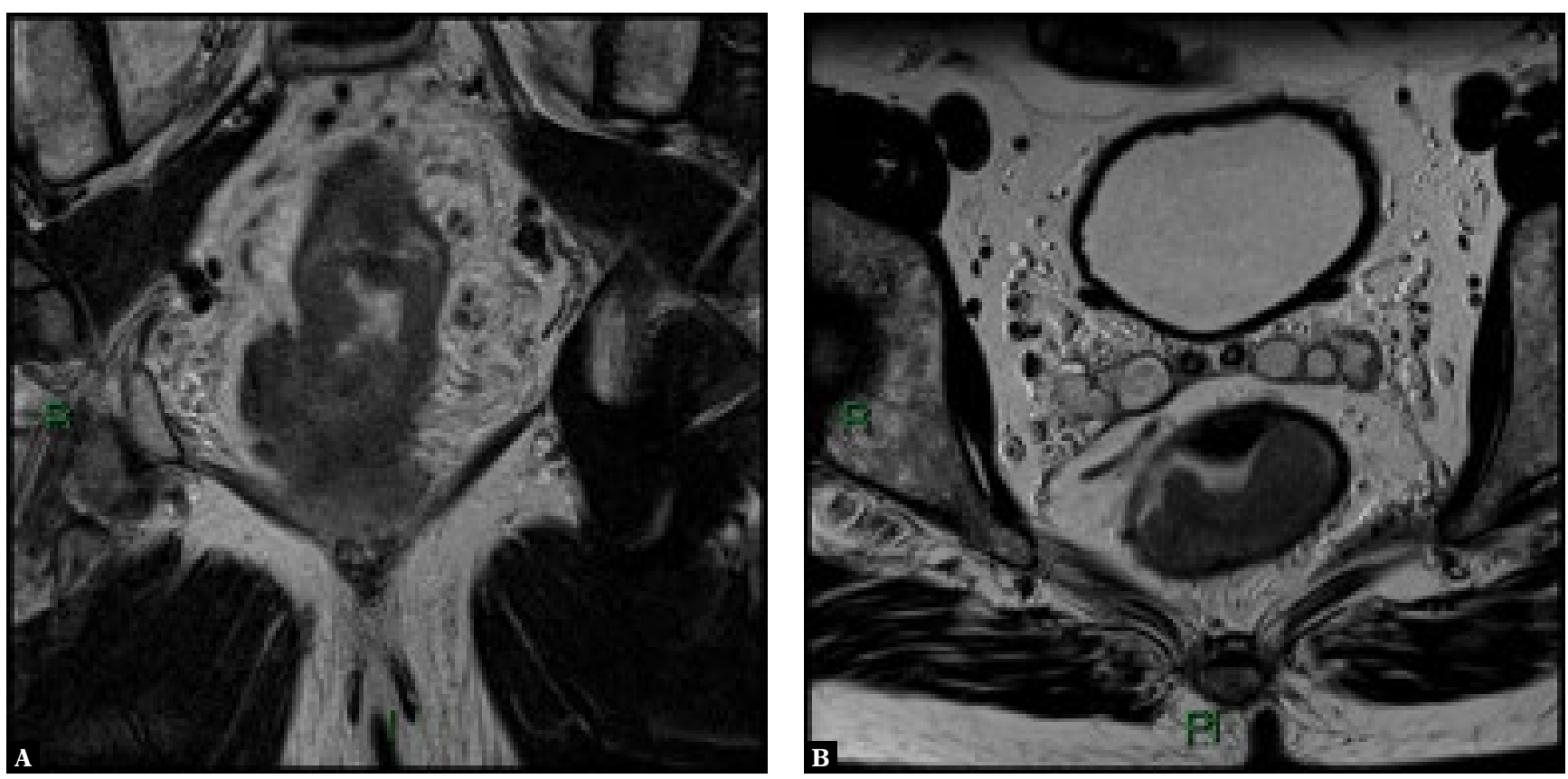

Fig. 3. Voluminous rectal tumor, evaluated by MRI in coronal (A) and axial (B) T2-weighted sections. On the coronal image, extensive invasion of the perirectal fat is seen

patients with known oncologic pathology (Fig. 2). Local staging of pelvic tumors, such as uterine, prostatic or rectal tumors, is an indication for MRI and not CT. The presence of gastric or colonic tumors needs to be confirmed using endoscopy. Virtual CT-colonoscopy can be used as a substitute for conventional colonoscopy for the diagnosis of colonic polyps and tumors. Follow-up of oncologic disease should in most cases be performed using CT.

\section{Postoperative complications}

Patients with abdominal pain, fever or developing biologic changes, such as leukocytosis or elevated CRP, after surgical procedures should be evaluated by $\mathrm{CT}$ to look for the presence of complications, e.g. an abscess or fistula.

\section{Follow-up of liver cirrhosis}

Patients with liver cirrhosis and nodules discovered on ultrasound screening should be evaluated by means of contrast-enhanced CT (CE-CT) or, preferably, contrastenhanced MRI (CE-MRI). CE-MRI has, when compared to $\mathrm{CT}$, higher sensitivity ( 0.82 vs 0.66$)$ and lower negative likelihood ( 0.20 vs 0.37$)$ for the diagnosis of nodules in a cirrhotic liver ${ }^{(30)}$.

\section{Evaluation of abdominal vessels}

CE-CT/CT angiography (CTA) is a very good imaging technique for assessing congenital or acquired abnormalities of the abdominal vessels, such as evaluation of abdominal aneurysms or atherosclerotic disease leading to occlusion or critical stenosis of the abdominal vessels. Aortic aneurysms should be periodically evaluated by means of CT-angiography.

\section{Magnetic resonance imaging}

MRI has become an essential tool for imaging the abdomen with the following indications summarised by the $\mathrm{ACR}^{(31)}$ (Tab. 4).

\section{Focal liver lesions}

Among the available imaging techniques, including positron emission tomography-computed tomography (PET-CT), MRI has the highest accuracy for the characterization of focal liver lesions in both cirrhotic and non-cirrhotic patients. With a combination of T1- and T2-weighted images, diffusion-weighted imaging (DWI), and injection of hepatobiliary agents, such as Gd-EOB-DTPA, the majority of focal liver lesions can be accurately characterized and a differential diagnosis between benign and malignant focal liver lesions can be made ${ }^{(32)}$. Overall, sensitivity and specificity of a complex MRI protocol, including DWI and Gd-EOB-DTPA injection, for detection and further classification of a focal liver lesion are high, ranging between 90 and $95 \%{ }^{(32)}$.

\section{Diffuse hepatic disease}

MRI can also be used to evaluate diffuse liver diseases. In liver cirrhosis, the main indication for MRI is detection of hepatocellular carcinoma. MRI is also very useful for 
predicting the grade of liver fibrosis, as there is a strong correlation between gadolinium accumulation in tissues in the late phases after injection and hepatic fibrosis. The diagnostic performance of MRI increases with the stage of liver fibrosis and is as high as 0.92 for fibrosis stage $4^{(33)}$. MRI can also be used for the detection and quantification of other diffuse liver diseases, such as hemochromatosis, hemosiderosis, and steatosis.

\section{Liver infections}

MRI is an appropriate technique for evaluating liver infections and detecting liver abscesses in inconclusive findings. Its sensitivity to identify small differences in tissue composition leads to a very good specificity for certain hepatic infections, including hydatid cyst and candidiasis. MR imaging shows $100 \%$ sensitivity and $96 \%$ specificity for the diagnosis of hepatosplenic fungal disease ${ }^{(34)}$.

\section{Pre- and postoperative liver evaluation}

In the evaluation of liver donors, liver transplants, and postoperative complications, MRI has advantages over other imaging techniques, particularly in the evaluation of post-transplant biliary pathology. Also, it can offer additional information to sonography-based techniques in the evaluation of posttransplant liver fibrosis. Magnetic resonance cholangiography provides a panoramic and detailed representation of the bile ducts, which is not achievable by other techniques. Accuracy of MRI in detecting posttransplant biliary strictures is as high as $92.3 \%{ }^{(35)}$.

\section{Biliary tract pathology}

MRI is an excellent technique for the assessment of biliary tract pathology. MRI may be preferred over CT for biliary tract pathology, because it has superior stone conspicuity and does not utilize ionizing radiation. It is preferred over diagnostic endoscopic retrograde cholangiopancreatography (ERCP), as the latter has high complication (3\%-9\%) and mortality rates $(0.2 \%-0.5 \%)^{(36)}$.

\section{Pancreatic disease}

MRI is also used in pancreatic disease, with the indications for pancreatic MRI including characterization of suspected parenchymal abnormalities found on computed tomography (CT) or ultrasound (US), detection and staging of pancreatic neoplasms as an adjunct to CT, characterization of cystic pancreatic lesions, detection of small non-organ-deforming pancreatic ductal adenocarcinomas, detection of neuroendocrine tumors, evaluation of acute and chronic pancreatitis when CT fails to be diagnostic, detection of choledocholithiasis as a cause of acute pancreatitis, detection of intraluminal pancreatic calculi and staging of chronic pancreatitis.

\section{Inflammatory bowel disease}

MRI of the abdomen with positive digestive contrast media (usually water with an osmotic agent) should be used for the assessment of the extent and complications of inflammatory bowel disease. MRI has comparable results to CT in the detection of complications of inflammatory bowel disease, such as stenosis and fistula formation. The lack of ionizing radiation makes MRI a better technique than CT, particularly in young patients, as patients with inflammatory bowel disease often require numerous imaging studies during their lifetime.

\section{Rectal tumors}

MRI is an indispensable imaging tool in the preoperative local staging of rectal tumors. An initial local staging is performed to determine which patients require preoperative radiochemotherapy, or to plan surgery in those who do not require radiochemotherapy. MRI has an excellent soft tissue contrast, which facilitates assessment of tumor spreading into the perirectal fat, involvement of the mesorectal fascia (which is an indication for preoperative radiotherapy) and involvement of the sphincteric complex. MRI is indicated before and after radiochemotherapy to assess the response to therapy (Fig. 3).

\section{Perianal fistulas}

MRI is the preferred imaging tool for the characterization of perianal fistulas. Imaging of perianal fistulas facilitates the detection of secondary fistulous tracts and the formation of abscesses. Information about the relationship between fistulous tracts and the sphincteric complex is also required by the surgeon prior to intervention ${ }^{(37)}$.

\section{Conclusions}

Imaging is an indispensable tool in abdominal pathology. Ultrasound is, in most cases, the first imaging technique used in abdominal pathology and can be sometimes sufficient for a complete diagnosis. CEUS has greatly improved the accuracy of ultrasound in characterizing focal liver lesions. CT, combined with US, is a very useful tool in traumatic and nontraumatic abdominal emergencies. MRI is a very useful technique for specific indications, like evaluating focal liver lesions or assesing rectal and perianal benign or malignant pathology.

\section{Conflict of interest}

The author does not report any financial or personal connections with other persons or organizations, which might negatively affect the contents of this publication and/or claim authorship rights to this publication.

\section{Acknowledgement}

The authors thank the Bad Mergentheimer Leberzentrum for support. 


\section{References}

1. Caraiani C, Dong Y, Rudd AG, Dietrich CF: Reasons for inadequate or incomplete imaging techniques. Med Ultrason 2018; 20: 498-507.

2. Caraiani C, Petresc B, Dong Y, Dietrich CF: Contraindications and adverse effects in abdominal imaging. Med Ultrason 2019; 21: 456-463.

3. Gee MS, Harisinghani MG: MRI in patients with inflammatory bowel disease. J Magn Reson Imaging 2011; 33: 527-534.

4. Mazzei MA, Guerrini S, Cioffi Squitieri N, Cagini L, Macarini L, Coppolino F et al.: The role of US examination in the management of acute abdomen. Crit Ultrasound J 2013; 5 Suppl 1: S6.

5. Kratzer W, Pfeiffer M, Gebel M, Dietrich C, Adler G: [The research situation in abdominal sonography in the gastroenterology departments of university hospitals in the Federal Republic of Germany]. Z Gastroenterol 2000; 38: 833-834, 836.

6. Laméris W, van Randen A, van Es HW, van Heesewijk JP, van Ramshorst B, Bouma WH et al.: Imaging strategies for detection of urgent conditions in patients with acute abdominal pain: diagnostic accuracy study. BMJ 2009; 338: b2431.

7. Dietrich CF, Gouder S, Hocke M, Schuessler G, Ignee A: Endosonographie der Choledocholithiasis und ihrer Differentialdiagnosen. Endoskopie Heute 2004; 17: 160-166.

8. Jagannath S, Garg PK: Recurrent acute pancreatitis: current concepts in the diagnosis and management. Curr Treat Options Gastroenterol 2018; 16: 449-465.

9. Dachille G, Erinnio M, Cardo G, Maselli FP, Vestita G, Ludovico GM: Detection rate of ultrasound vs CT scan in clinical staging accuracy of renal tumors pT1NxMx. Arch Ital Urol Androl 2005; 77: 149-150.

10. Stamatiou K, Papadoliopoulos I, Dahanis S, Zafiropoulos G, Polizois K: The accuracy of ultrasonography in the diagnosis of superficial bladder tumors in patients presenting with hematuria. Ann Saudi Med 2009; 29: 134-137.

11. Barker CS, Lindsell DR: Ultrasound of the palpable abdominal mass. Clin Radiol 1990; 41: 98-99.

12. Dietrich CF, Wehrmann T, Zeuzem S, Braden B, Caspary WF, Lembcke B: [Analysis of hepatic echo patterns in chronic hepatitis C]. Ultraschall Med 1999; 20: 9-14.

13. Bernatik T, Schuler A, Kunze G, Mauch M, Dietrich CF, Dirks K et al.: Benefit of contrast-enhanced ultrasound (CEUS) in the follow-up care of patients with colon cancer: A prospective multicenter study. Ultraschall Med 2015; 36: 590-593.

14. Sidhu PS, Cantisani V, Dietrich CF, Gilja OH, Saftoiu A, Bartels E et al.: The EFSUMB guidelines and recommendations for the clinical practice of contrast-enhanced ultrasound (CEUS) in non-hepatic applications: Update 2017 (short version). Ultraschall Med 2018; 39: 154-180.

15. Nural MS, Yardan T, Guven H, Baydin A, Bayrak IK, Kati C: Diagnostic value of ultrasonography in the evaluation of blunt abdominal trauma. Diagn Interv Radiol 2005; 11: 41-44.

16. Riemann B, Menzel J, Schiemann U, Domschke W, Konturek JW: Ultrasound-guided biopsies of abdominal organs with an automatic biopsy system. A retrospective analysis of the quality of biopsies and of hemorrhagic complications. Scand J Gastroenterol 2000; 35: 102-107.

17. Rudralingam V, Footitt C, Layton B: Ascites matters. Ultrasound 2017; 25: 69-79.

18. Sorantin E, Lindbichler F: Management of intussusception. Eur Radiol 2004; 14 Suppl 4: L146-154.

19. Strobel D, Seitz K, Blank W, Schuler A, Dietrich C, von Herbay A et al.: Contrast-enhanced ultrasound for the characterization of focal liver lesions - diagnostic accuracy in clinical practice (DEGUM multicenter trial). Ultraschall Med 2008; 29: 499-505.

20. Jhaveri KS, Hosseini-Nik H: MRI of rectal cancer: An overview and update on recent advances. AJR Am J Roentgenol 2015; 205: W42-55.

21. Rodger F, Roditi G, Aboumarzouk OM: Diagnostic accuracy of low and ultra-low dose CT for identification of urinary tract stones: A systematic review. Urol Int 2018; 100: 375-385.

22. Stapakis JC, Thickman D: Diagnosis of pneumoperitoneum: abdominal CT vs. upright chest film. J Comput Assist Tomogr 1992; 16: 713-716.

23. García-Blázquez V, Vicente-Bártulos A, Olavarria-Delgado A, Plana MN, van der Winden D, Zamora J et al.: Accuracy of CT angiography in the diagnosis of acute gastrointestinal bleeding: systematic review and meta-analysis. Eur Radiol 2013; 23: 1181-1190.

24. Mallo RD, Salem L, Lalani T, Flum DR: Computed tomography diagnosis of ischemia and complete obstruction in small bowel obstruction: a systematic review. J Gastrointest Surg 2005; 9: 690-694.

25. Wiesner W, Khurana B, Ji H, Ros PR: CT of acute bowel ischemia. Radiology 2003; 226: 635-650.

26. Petrowsky H, Raeder S, Zuercher L, Platz A, Simmen HP, Puhan MA et al.: A quarter century experience in liver trauma: a plea for early computed tomography and conservative management for all hemodynamically stable patients. World J Surg 2012; 36: 247-254.

27. Brofman N, Atri M, Hanson JM, Grinblat L, Chughtai T, Brenneman F: Evaluation of bowel and mesenteric blunt trauma with multidetector CT. Radiographics 2006; 26: 1119-1131.

28. Gupta A, Stuhlfaut JW, Fleming KW, Lucey BC, Soto JA: Blunt trauma of the pancreas and biliary tract: a multimodality imaging approach to diagnosis. Radiographics 2004; 24: 1381-1395.

29. Jamis-Dow CA, Choyke PL, Jennings SB, Linehan WM, Thakore KN, Walther MM: Small $(<$ or $=3-\mathrm{cm}$ ) renal masses: detection with CT versus US and pathologic correlation. Radiology 1996; 198: 785-788.

30. Roberts LR, Sirlin CB, Zaiem F, Almasri J, Prokop LJ, Heimbach JK et al.: Imaging for the diagnosis of hepatocellular carcinoma: A systematic review and meta-analysis. Hepatology 2018; 67: 401-421.

31. ACR-SAR-SPR practice parameter for the performance of magnetic resonance Imaging (MRI) of the liver.

32. Albiin N: MRI of focal liver lesions. Curr Med Imaging Rev 2012; 8: 107-116.

33. Petitclerc L, Gilbert G, Nguyen BN, Tang A: Liver fibrosis quantification by magnetic resonance imaging. Top Magn Reson Imaging 2017; 26: 229-241.

34. Semelka RC, Kelekis NL, Sallah S, Worawattanakul S, Ascher SM: Hepatosplenic fungal disease: diagnostic accuracy and spectrum of appearances on MR imaging. AJR Am J Roentgenol 1997; 169: 1311-1316.

35. Cereser L, Girometti R, Como G, Molinari C, Toniutto P, Bitetto D et al.: Impact of magnetic resonance cholangiography in managing liver-transplanted patients: preliminary results of a clinical decisionmaking study. Radiol Med 2011; 116: 1250-1266.

36. Soto JA, Barish MA, Yucel EK, Siegenberg D, Ferrucci JT, Chuttani R: Magnetic resonance cholangiography: comparison with endoscopic retrograde cholangiopancreatography. Gastroenterology 1996; 110: 589-597.

37. Morris J, Spencer JA, Ambrose NS: MR imaging classification of perianal fistulas and its implications for patient management. Radiographics 2000; 20: 623-635; discussion 35-37. 